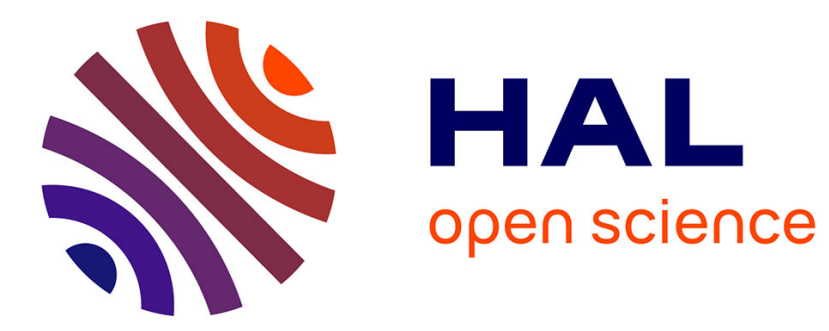

\title{
Appliances Modeling And Simulation: A Virtual Platform Applied For Arc Fault Testing
}

Jinmi Lezama, Patrick Schweitzer, Serge Weber, Etienne Tisserand, Patrice Joyeux

\section{- To cite this version:}

Jinmi Lezama, Patrick Schweitzer, Serge Weber, Etienne Tisserand, Patrice Joyeux. Appliances Modeling And Simulation: A Virtual Platform Applied For Arc Fault Testing. 2018 IEEE PES Transmission \& Distribution Conference and Exhibition - Latin America (T\&D-LA), Sep 2018, Lima, France. pp.1-5, 10.1109/TDC-LA.2018.8511672 . hal-02065655

\section{HAL Id: hal-02065655 \\ https://hal.univ-lorraine.fr/hal-02065655}

Submitted on 12 Mar 2019

HAL is a multi-disciplinary open access archive for the deposit and dissemination of scientific research documents, whether they are published or not. The documents may come from teaching and research institutions in France or abroad, or from public or private research centers.
L'archive ouverte pluridisciplinaire HAL, est destinée au dépôt et à la diffusion de documents scientifiques de niveau recherche, publiés ou non, émanant des établissements d'enseignement et de recherche français ou étrangers, des laboratoires publics ou privés. 


\title{
Appliances Modeling And Simulation: A Virtual Platform Applied For Arc Fault Testing
}

\author{
Jinmi LEZAMA*, Patrick SCHWEITZER ${ }^{\dagger}$, Serge WEBER $^{\dagger}$, Etienne TISSERAND ${ }^{\dagger}$, Patrice JOYEUX ${ }^{\ddagger}$ \\ ${ }^{*}$ Instituto Nacional de Investigación y Capacitación de Telecomunicaciones - INICTEL-UNI \\ Universidad Nacional de Ingeniería \\ †Université de Lorraine \\ $\ddagger$ Hager Electro SAS \\ Email: jlezama@inictel-uni.edu.pe,pschweitzer@univ-lorraine.fr
}

\begin{abstract}
This study is devoted to the development of a virtual electric network composed by linear and nonlinear household appliances, the supply voltage and an arc fault which can be inserted in series or in parallel in the line. The configuration and composition of the entire device can be changed at will. This virtual platform is used to the establishment of a current and line voltage signatures database for the development of an arc fault detector. We describe in this paper some load modeling using both Matlab/simulink (for the performed universal motor model) and SimPowerSystem block (for the supply voltage, wires and arc models). The simulation platform presented includes a vacuum cleaner, a discharge lamp, a drill and an electric arc fault. Validation criteria of the different models are based on the comparison of the harmonic distortion (frequency characteristic) and the calculus of the index of agreement (time characteristic). The experimental results obtained validate the models for single and combined loads in the presence or not of an arc in series in the electric line.
\end{abstract}

Index Terms-modelling, domestic loads, arc fault, detection

\section{INTRODUCTION}

An electrical arc fault particularly in a domestic installation is a dangerous phenomenon that may cause fire ignitions. In 2010, an estimation of 46500 fires in the home structures [1] caused by an apparatus malfunction or electrical failure (mainly by over-current, short-circuit, insulation fault or worst contact) have been reported. The development of arc faults detectors [2] [3] based mostly on the electrical current and line voltage signatures requires a large signals database reproducing many different situations according to the number and type of loads on the network (single loads, combined loads, parallel and series arc.).

In order to get away from an experimental phase, which can often be complicated to set up, we opted for an approach based on the development of a configurable virtual domestic network which operates closest to the reality.

The choice of simulation software to develop the entire virtual network is essential. Although all the domestic network loads are electrical ones (including power devices), others may require the modeling of electromechanical and mechanical devices. The software platform should also allow the simulation of both the numerical detection system and our home network model [4]. All simulations are performed with MatLab/Simulink - SimPowerSystem software.
On the same, loads modeled with other software (Pspice, Psim ....) can be easily integrated in the virtual network.

Fig. 1 shows the general diagram of the power line model. It contains a power supply (230 VAC $-50 \mathrm{~Hz})$, a circuit breaker, the electrical wires and also the different domestic loads (simple or combined associations). The electrical arcing fault occurs either in serial or in parallel mode. The circuit breaker which analyzes the current and voltage on the line is located upstream of the line to be protected, but will not be modeled in this study.

The main objective is to get the electrical signatures (line current and voltage) unique and specific to each device and to build a complete database.

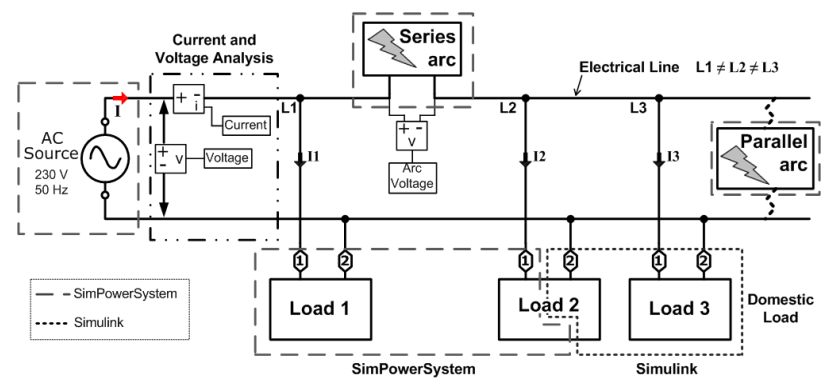

Fig. 1: Electrical network model including models of arc fault on Simulink.

In the literature, main modellings concern linear and nonlinear loads largely used for domestic application. Several models of domestic and industrial loads have been developed such as personal computers [5] [6], fluorescent lamp [5], adjustable speed drives [5]. Modeling presented in this work will principally focus on a vacuum cleaner and the drill with an improved electric motor model. In literature, Di Gerlando et al. [7] [8] propose a transient model of a universal motor model by modeling the influences of the saturation inductances and taking into account the constructional quantities of the machine. Tuncay [9] present a universal motor model for a vacuum cleaner. In our work, we favored a modelling of the DC engine which not require the knowledge of all the parameters necessary for the previous models. The modelling is based on the electric and mechanical equations of the engine. The modelling of the drill as well as the vacuum 


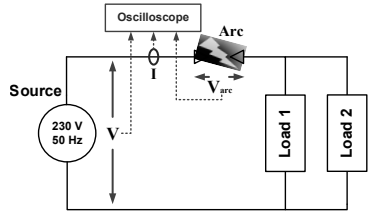

(a) Circuit

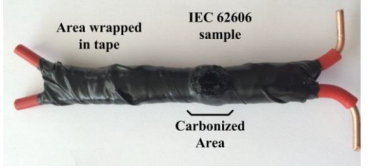

(b) wire
Fig. 2: Experimental test

cleaner is obtained by adding the modules of torque functions and power variation appropriate to every device to obtain the current line signature the closest to the reality.

The results of current and voltage are obtained experimentally with simple load and also with combined loads. Moreover, these two configurations are reproduced with a series arc fault on the line. For each test, we compare experimental and simulate results using the total harmonic distortion THD (frequency characteristic) and the index of agreement (time characteristic).

\section{Test Set Up and Models Validation}

In order to evaluate the performance of the model, simulated and measured current signatures are compared both by harmonic analysis (total harmonic distortion- THD) and shape analysis (index of agreement).

\section{A. Models validation}

The THD is defined as the ratio of the rms value of the total harmonics to the rms value of the fundamental component according to equation (1):

$$
\text { THD } \%=\frac{\sqrt{\sum_{n=2,3,4}^{20} h_{n}^{2}}}{h_{1}} * 100 \%
$$

The index of agreement (d) [10] is estimated according to (2) from the simulated value $\mathrm{P}$, the observed value $\mathrm{O}$ and the observed mean value $\bar{O}$.

$$
d=1-\frac{\sum_{i=1}^{k}\left(O_{i}-P_{i}\right)^{2}}{\sum_{i=1}^{k}\left[\left|P_{i}-\bar{O}\right|+\left|O_{i}-\bar{O}\right|\right]^{2}}
$$

\section{B. Experimental test set up}

Fig. 2 shows the schematic configuration of experimental system (arc fault generation and data acquisition). A series arc fault is generated using carbonized path [11] [12] [13] between two domestic copper wires [11], the circuit is powered with $230 \mathrm{VAC} / 50 \mathrm{~Hz}$.

The characteristics of the current and voltage probes are given in the table I. Data acquisition is carried out by a Lecroy oscilloscope wavepro $950(1 \mathrm{GHz})$.
TABLE I: Current and Voltage characteristics

\begin{tabular}{ccc}
\hline Load & Voltage & Current \\
\hline Model & Lecroy PPe 20 kV & Lecroy AP015 \\
Bandwidth & DC $-100 \mathrm{MHz}$ & DC $-50 \mathrm{MHz}$ \\
Max. peak & $20 \mathrm{kV}$ & $50 \mathrm{~A}$ \\
\hline
\end{tabular}
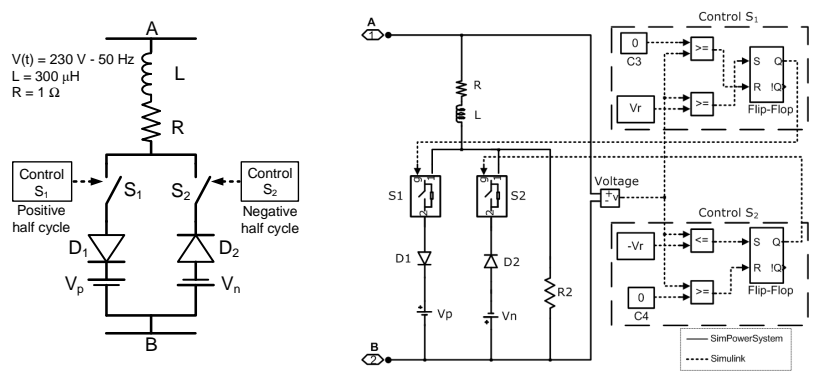

Fig. 3: Electrical model and simulation diagram of an arc fault.

\section{Arc FAult Modeling}

Many authors have proposed models to describe an arcing fault. Emanuel et al. [14] as for them proposed a model with two DC sources connected in opposite direction by means of two diodes and two voltage sources representing the arc voltage. Etemadi et al. [15] uses the same model and adds two resistances, $R_{p}$ and $R_{n}$ which represent the fault resistance. Based on the other models, Zamanan et al. [16] [17] proposed a dynamic by adding two inductances Lp and Ln which introduce nonlinearity in the V-I curve. Sedighi et al. [18] used combinations of nonlinear varying resistor and also introduced a switch controlling the loop opening and closing. Our model based on the Zamanans one [16] [17] and Andrea [19], comprises a switch control to generate the arc restrike voltage. When the line voltage reached the restrike voltage $\left(V_{r}\right)$, the switch is closed so the current flows across the arc circuit. Restrike voltage $V_{r}$ can be set differently depending on the positive or negative half cycle. The arc voltage reaches $V_{p}$ or $V_{n}$. The switch $\mathrm{S}$ is opened at each zero crossing. Fig. 3 shows the block diagram of the arc fault and model implemented with Matlab Simulink / SimPowerSystem.

The values of the parameters used for modeling. Diodes are considered ideal. $V_{r}=60 \mathrm{~V}, V_{p}=V_{n}=25 \mathrm{~V}, \mathrm{R}=4 \Omega$ and $\mathrm{L}=$ $400 \mu H$.

The comparison of measured and modeled current curves is presented on Fig. 4. The two currents signatures present a great similarity $(\mathrm{d}=98.03 \%)$. Some differences appear especially at the arc ignition.

The results show that the harmonic content of the measured and modeled signals are of the same order (THD meas = $30.06 \%$ and THD model $=38.32 \%$ ).

In both cases, the harmonics amplitude of order 1, 3 and 5 prevails. The values given by the modelling are however superior to the values measured for all the odd orders. These differences are mainly related to symmetry of the arc signal 


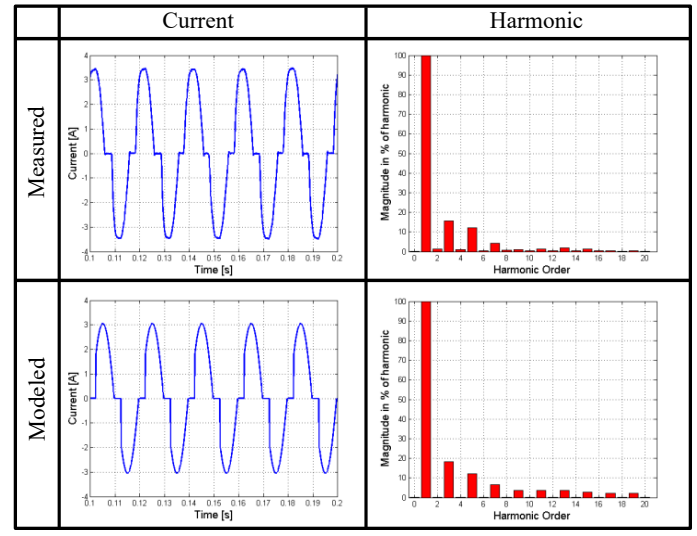

Fig. 4: Current arc fault signatures.

in the model while it is not completely the case in the reality. Furthermore, the arc signal is widely chaotic in time, its physical characteristics being modified from one period to the other one, phenomenon which is not taken into account in the model.

The harmonics amplitudes of even order are very low as well for the measured signal and the modelled one. In the modelling, the signal of current being perfectly symmetric, the even harmonics are equal to zero.

\section{Domestic Load Modeling}

We have used the classification of all domestic loads proposed by Ting et al. [20] based on four types of loads (resistive, inductive, rectified load and motor) as shown in Fig. 5.

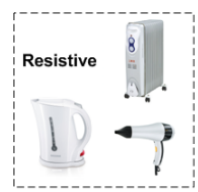

Resistance, kettle, hair dryer, etc...

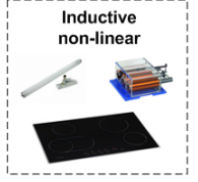

Ballasts for lighting devices, etc...

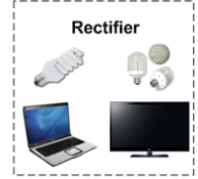

Personal computer, light LED, battery charger, etc.

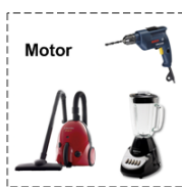

Vacuum cleaner, drill, fans, etc.
Fig. 5: Load Signature classification.

Resistive loads (kettle, hair dryer, ...) relatively simple to be modeled will not be taken into account in this work. This is also the case of rectifier type loads, usually equipped with power factor corrector module. Among the inductive / nonlinear loads, we present the model of the domestic appliances based on a universal motor will also be developed.

\section{A. Universal motor model}

1) Electrical and mechanical part modeling: Universal motor is widely used in many domestic appliances (washing machine, mixer, blender, drill). It can operate with a single AC supplies and also with DC supplies. In the universal motor, the stator and rotor windings are connected in series [7] [8] [21]. The model we propose added the torque functions and power variation. These functions allow us to take into account the variation of current due to fluctuations of torque electromagnetic and also the current evolution. Fig. 6 shows the blocks diagram of the universal motor which is described traditionally by three equations: electrical part (3), mechanical part (4) and load torque.

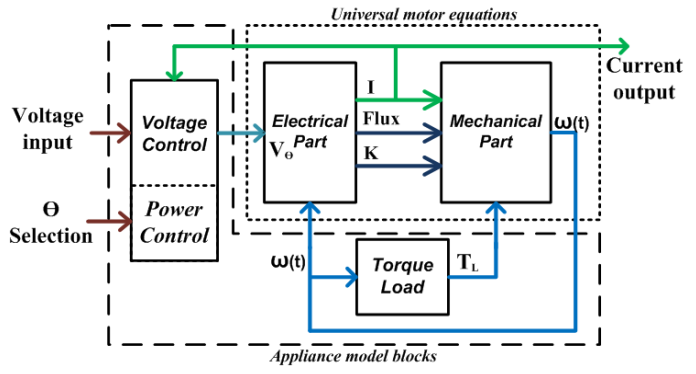

Fig. 6: Diagram for appliance using a universal motor.

- The electrical part

$$
u(t)-\left(L_{a}+L_{f}\right) \frac{d}{d t} i(t)-e(t)=\left(R_{a}+R_{f}\right) i(t)
$$

- The mechanical part

$$
T_{e}(t)=T_{L}+D * w_{m}+J \frac{d}{d t} w_{m}
$$

Where: $R_{a}$ is the rotor winding resistance. $R_{f}$ is the stator winding resistance. $L_{a}$ is the rotor winding inductance. $L_{f}$ is the stator winding inductance. $u(t)$ is the input voltage. $e(t)$ is the electromotive force. $i(t)$ is the current. $J$ is the moment of inertia. $\mathrm{D}$ is the viscousdamping constant. $T_{e}(t)$ is the electromagnetic torque. $T_{L}$ is the load torque. $\omega_{m}(t)$ is the angular velocity.

Fig. 7 shows the electrical modeling of the motor inserted on the line. The appliance is modeled using matlab simulink and the electrical network by SimPowerSystem.

The general supply voltage and the propagation line being modelled under SimpowerSystem, a load modeled in Simulink can not be directly inserted into the resulting network. It is thus necessary to inject the consumption current of every load in the general electric line by a controlled current source block connected in close loop. "This will have for consequence that any disturbance related in particular to a defect of electric arc which can occur upstream to the load is going to injected on the entrance of this one through the current and the voltage of line".

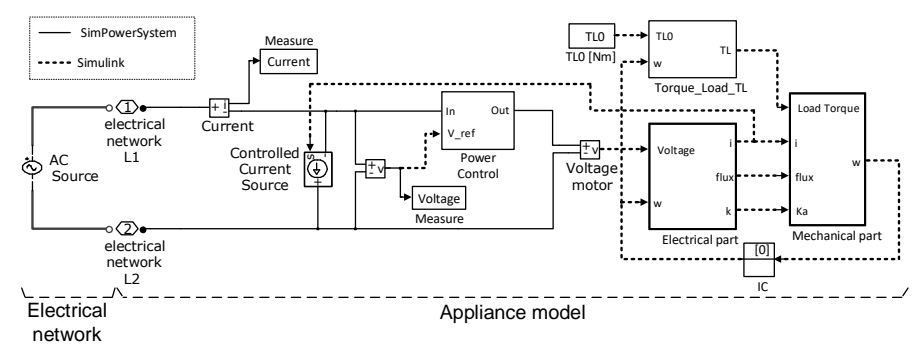

Fig. 7: Appliance model in Matlab Simulink 


\section{RESULTS}

\section{A. Drill with an Arc Fault}

In this test an arc fault in series with a drill is presented (Fig. 8)

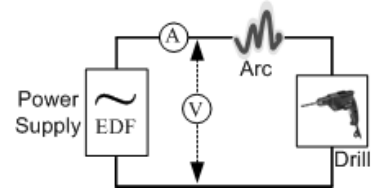

Fig. 8: Drill in series with an arc fault.

Fig. 9 shows the measured and simulated current, harmonic analysis and the validation criteria values.

Fig. 10 shows a good agreement between the current experimental and the current measured, $d$ reaches $97.73 \%$.

The presence in the model of a zero crossing current can explain the relatively important difference of the 3 order harmonic amplitude between the model and the measurement. The difference between amplitude of odd harmonics (THD meas $=24.79 \%$, THD model $15.75 \%$ ) can be related to the fact that several parameters such as switching of the collector's for the drill model and spark effect in the arc fault model are not taken into account in the modelling. Furthermore, the modelled current is perfectly symmetric and doesnt contains any offset voltage.

The global THD values for measured and simulated currents have a difference of about $7 \%$, $(\mathrm{TDH}$ meas $=25.01 \% \mathrm{TDH}$ model $=15.76 \%$ ) due to parameters described before. The amplitudes of even harmonics are close to zero for the whole orders. The presence of an offset voltage on the probe is translated by a rather strong value of the continuous component.

\section{B. Masking Load}

Masking load consists in two or more loads connected in parallel, wherein a series arcing fault occurs in the circuit. This test is composed by a vacuum cleaner in parallel with a radiator in series with an arc fault (Fig. 11).

TABLE II: Simulation parameters of Fig. 11.

\begin{tabular}{cc}
\hline \multicolumn{2}{c}{ Simulation parameters } \\
\hline Voltage & $120 \mathrm{~V} / 50 \mathrm{~Hz}$ \\
\hline $\begin{array}{l}\text { Vaccum } \\
\text { cleaner }\end{array}$ & $\begin{array}{c}\text { Power } 750 \mathrm{~W} \\
\text { Load torque } 0.5 \mathrm{Nm} \\
\text { Phase control } 60^{\circ}\end{array}$ \\
\hline Resistance & $\mathrm{R}=11 \Omega$ \\
\hline
\end{tabular}

Fig. 12 shows the results both for simulation and modeling. The good index of agreement $(99.7 \%)$ shows the great similarity between simulated and measured current waveform

By taking into account three different loads on the line, the total distortion harmonic global in both cases is similar (THD meas $=15.29 \%$ THD model $=16.75 \%)$. The most pronounced difference concerns the 7 and 9 harmonics order to a lesser extent. For odd harmonics, the rates of distortions remain however rather close (THD odd meas $=15.18 \%$, THD odd model $16.75 \%$ ). These variations are due to some parameters from load model (motor torque and line voltage variation) and arc model that are not taken in account. For the even harmonics, the values are very low in both cases (THD even meas $=1.82 \%$, THD even model $0.23 \%$ ).

\section{CONCLUSIONS}

In this paper, a simulation platform has been presented in order to recreate a virtual domestic electrical installation. This platform is an essential tool for the development and testing, in a reliable way, of arc fault detection methods based on the supervision of the current and voltage on the electric line. THD estimation and index of agreement value are two pertinent indicators allowing to compare current signatures from modeling and measurement.

In order to model a drill and a vacuum cleaner, we took back the equations of the literature describing the electric and mechanical part of a universal motor to which we added the power and torque regulation modulus. We showed that it was possible to develop the different domestic load models using both MatLab Simulink and SimPowerSystem. All simulink/SPS models are presented in details and compared with experimental measurements.

A good concordance in the calculation of the total harmonic distortion and a value of the index of agreement upper to 0.95 shows also that simulated curves are in good concordance with experimental ones. The good agreement between experimental and modeled results concern both the case of single and combined loads. The results showed the possibility to build many different configurations of the electric network by varying the number and type of loads. Furthermore, an arcing fault model can be inserted anywhere in the electric line.

The future works will concern the development of simulation models of other types of loads (PC compute, television) to complete the database for domestic installation modeling including the presence of an arc fault in the circuit.

\section{ACKNOWLEDGMENT}

The authors are grateful to Hager Group for their support on the work.

\section{REFERENCES}

[1] F. 2010, "Topycal fire report series: Residential building electrical fires," United States Fire Administration, 2012.

[2] UL1699, "Ul standard for safety for arc-fault circuit-interrupter," Underwriters Laboratories Inc., vol. 2nd edition revisions august 29, 2008.

[3] IEC62606, "General requirements for arc fault detection devices," International Electrotechnical Commission, July 09, 2013.

[4] J. Lezama, P. Schweitzer, S. Weber, E. Tisserand, and P. Joyeux, "Modeling of a domestic electrical installation to arc fault detection," in 2012 IEEE 58th Holm Conference on Electrical Contacts (Holm), Sept 2012, pp. 1-7.

[5] C. Venkatesh, D. S. Kumar, D. S. Sarma, and M. Sydulu, "Modelling of nonlinear loads and estimation of harmonics in industrial distribution system," in Fifteenth National Power Systems Conference (NPSC), IIT Bombay, 2008, pp. 592-597.

[6] R. Patidar and S. Singh, "Harmonics estimation and modeling of residential and commercial loads," in Power Systems, 2009. ICPS'09. International Conference on. IEEE, 2009, pp. 1-6. 


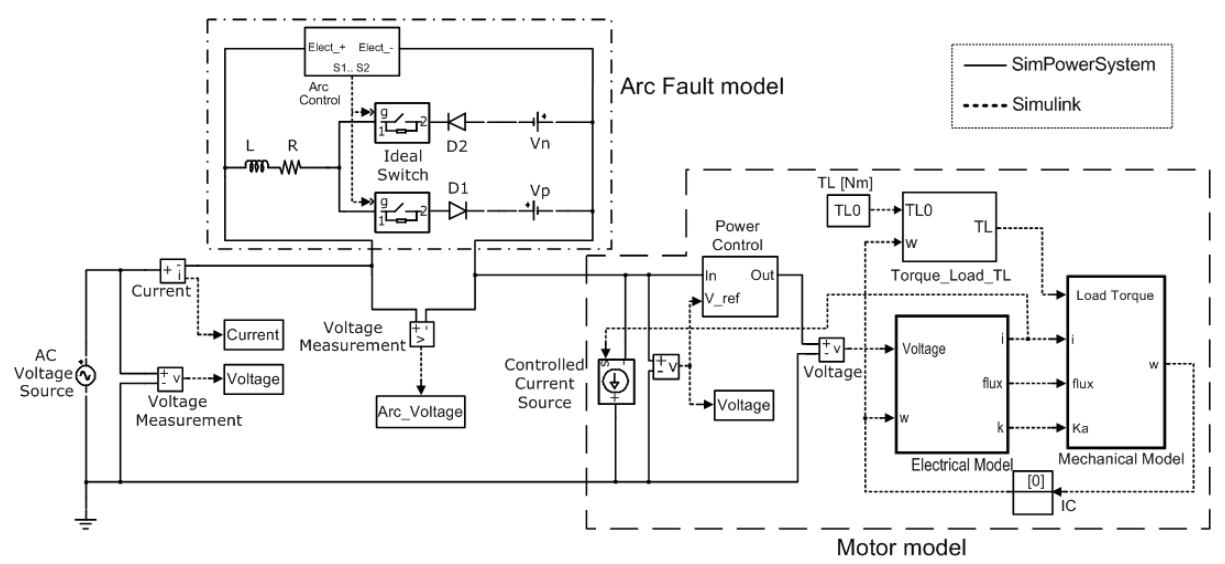

Fig. 9: Drill in series with an arc fault model.

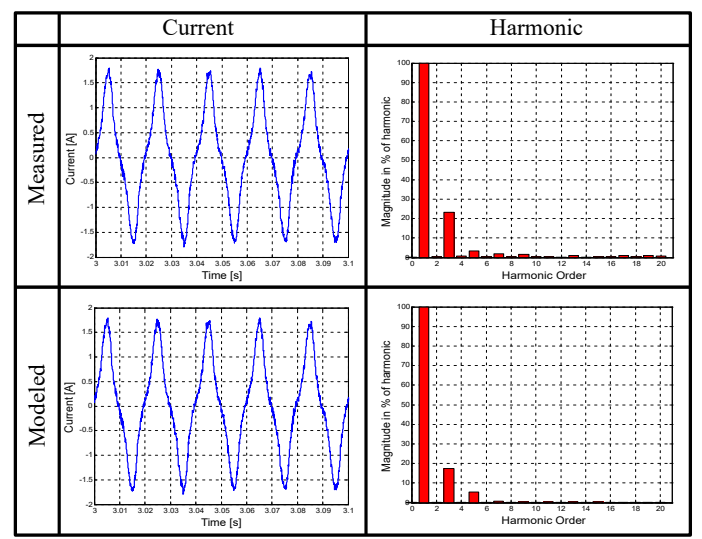

Fig. 10: Measured and simulated current for an arc fault in series with a drill.

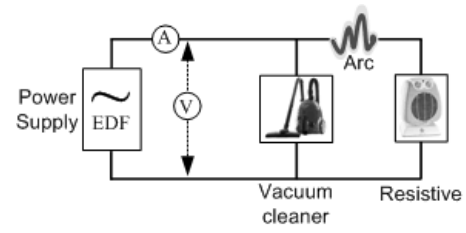

Fig. 11: Vacuum cleaner with an arc fault and drill configuration.

[7] A. Di Gerlando and R. Perini, "Modelling and test validation of high speed universal motors fed via a triac," in Electric Machines and Drives, 2005 IEEE International Conference on. IEEE, 2005, pp. 6-pp.

[8] A. Di Gerlando, R. Perini, and G. Rapi, "Equivalent circuit for the performance analysis of universal motors," IEEE Transactions on Energy Conversion, vol. 19, no. 1, pp. 18-27, 2004.

[9] R. Tuncay, M. Yilmaz, and C. Onculoglu, "The design methodology to develop new-generation universal-motors for vacuum cleaners," in Electric Machines and Drives Conference, 2001. IEMDC 2001. IEEE International. IEEE, 2001, pp. 926-930.

[10] C. J. Willmott, "On the validation of models," Physical geography, vol. 2, no. 2, pp. 184-194, 1981.

[11] J. J. Shea, "Identifying causes for certain types of electrically initiated fires in residential circuits," Fire and Materials, vol. 35, no. 1, pp. 19-42, 2011.

[12] J.-M. Martel, M. Anheuser, and F. Berger, "A study of arcing fault in the low-voltage electrical installation," in 2010 Proceedings of the 56th

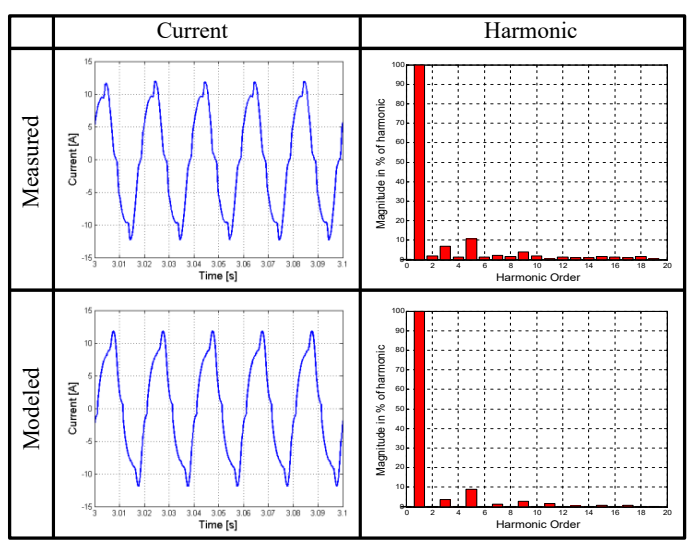

Fig. 12: Measured and simulated for masking load.

IEEE Holm Conference on Electrical Contacts, 2010.

[13] J. Andrea, P. Schweitzer, E. Tisserand, P. Roth, and S. Weber, "Calibrated ac and dc arcing fault generator," in 2010 Proceedings of the 56th IEEE Holm Conference on Electrical Contacts, 2010.

[14] A. Emanuel, D. Cyganski, J. Orr, S. Shiller, and E. Gulachenski, "High impedance fault arcing on sandy soil in $15 \mathrm{kv}$ distribution feeders: contributions to the evaluation of the low frequency spectrum," IEEE Transactions on Power Delivery, vol. 5, no. 2, pp. 676-686, 1990.

[15] A. Etemadi and M. Sanaye-Pasand, "High-impedance fault detection using multi-resolution signal decomposition and adaptive neural fuzzy inference system," IET generation, transmission \& distribution, vol. 2, no. 1 , pp. 110-118, 2008.

[16] N. Zamanan, J. Sykulski, and A. Al-Othman, "Arcing high impedance fault detection using real coded genetic algorithm," Third IASTED Asian Conference Power and Energy Systems, 2007.

[17] N. Zamanan and J. K. Sykulski, "Modelling arcing high impedances faults in relation to the physical processes in the electric arc," WSEAS Transactions on power systems, vol. 1, no. 8, pp. 1507-1512, 2006.

[18] A. Sedighi and M. Haghifam, "Simulation of high impedance ground fault in electrical power distribution systems," in Power System Technology (POWERCON), 2010 International Conference on. IEEE, 2010, pp. 1-7.

[19] J. Andrea, P. Schweitzer, and J.-M. Martel, "Arc fault model of conductance. application to the ul1699 tests modeling," in Electrical Contacts (Holm), 2011 IEEE 57th Holm Conference on. IEEE, 2011, pp. 1-6.

[20] K. Ting, M. Lucente, G. S. Fung, W. Lee, and S. Hui, "A taxonomy of load signatures for single-phase electric appliances," in IEEE PESC (Power Electronics Specialist Conference), 2005, pp. 12-18.

[21] P. Zhou, J. R. Brauer, S. Stanton, Z. J. Cendes, and R. Ebben, "Dynamic modeling of universal motors," in Electric Machines and Drives, 1999. International Conference IEMD'99. IEEE, 1999, pp. 419-421. 